\title{
Outcomes of cardiac surgical treatment for carcinoid heart disease
}

\author{
Sonia J Konsek-Komorowska', Agnieszka D Kolasińska-Ćwikła², Jacek Różański ${ }^{3}$ Krzysztof Bartuś4, \\ Jarosław Kuriata ${ }^{3}$, Marek Konka ${ }^{3}$, Ewa Sitkowska-Rysiak³ ${ }^{3}$ Ilona Michałowska ${ }^{3}$, Elżbieta Florczak³, \\ Maria Jaworska-Wilczyńska³, Andrzej Januszewicz³, Tomasz Hryniewiecki³, Jarosław B Ćwikła', \\ Mariola Pęczkowska ${ }^{3}$
}

\author{
'Department of Cardiology and Internal Medicine, School of Medicine, Collegium Medicum, University of Warmia and Mazury in Olsztyn, Olsztyn, Poland \\ ${ }^{2}$ The Maria Skłodowska-Curie National Research Institute of Oncology, Warszawa, Poland \\ ${ }^{3}$ National Institute of Cardiology, Warszawa, Poland \\ ${ }^{4}$ Department of Cardiovascular Surgery and Transplantology, Institute of Cardiology, Jagiellonian University Medical College, Kraków, Poland
}

\section{Correspondence to:}

Sonia J Konsek-Komorowska, MD, Department of Cardiology and Internal Medicine,

School of Medicine, Collegium Medicum,

University of Warmia and Mazury in Olsztyn,

Al. Warszawska 30; 10-082

Olsztyn, Poland,

phone: +48 895245389 ,

e-mail: sonia.konsek@interia.pl

Copyright by the Author(s), 2022

DOI: 10.33963/KP.a2021.0189

Received:

November 12, 2021

Accepted:

December 23, 2021

Early publication date:

December 23, 2021

\section{INTRODUCTION}

Neuroendocrine neoplasms of the small intestine (SI-NENs) originate in the midgut and are the third most common subtype of neuroendocrine neoplasms (NENs) in the gastroenteropancreatic system [1]. Carcinoid syndrome (CS) is the most prevalent paraneoplastic disease characterized by signs and symptoms related to the hormonal activity of SI-NENs. The classic type of CS is characterized by increased production of serotonin and/or other biologically active substances such as histamine, kallikrein, prostaglandins, and tachykinin [1, 2].

Carcinoid heart disease (CHD) is the most severe consequence of $\mathrm{CS}$, characterized by fibrotic valve degeneration, particularly in the right heart chambers. Nguyen et al. described indications requiring valve surgery, including progressive right heart failure (HF) and echocardiographic findings of moderate to severe right-sided valve regurgitation [3]. Valve surgery has been found to decrease right $\mathrm{HF}$, boost functional capacity, allow for more aggressive oncological therapy, and improve long-term prognosis in CHD patients. It is critical to plan surgery with preoperative dietary optimization and somatostatin analog therapy for carcinoid hormonal activity [4].

The Mayo Clinic's 30-year study involving 240 CHD-operated patients [3] represents the largest such study, with several shorter case series having also been published [5-7].
This retrospective study aimed to evaluate the medical data of operated patients with $\mathrm{CHD}$, including tumor characteristics, indications for valve replacement, complications, and mortality.

\section{METHODS}

The protocol for this retrospective single-center cohort study was authorized by the institution's ethics committee (no. 18/2018) and had signed informed consent from all patients. The subject group was selected from a data set of 275 patients with SI-NEN confirmed in pathological examination, diagnosed and treated between 2004 and 2019. In all the cases, a pathologist specializing in NEN verified and reported the histology results, which provided details on the histological grade and the stage of the neuroendocrine neoplasm (TNM) according to the American Joint Committee on Cancer (AJCC)/ /Union for International Cancer Control (UICC) 2017 classification.

Transthoracic echocardiography (TTE) was used to screen patients with CS for CHD on a frequent basis if their 5 -hydroxyindoleacetic acid or/and N-terminal pro-brain type natriuretic peptide levels were significantly elevated or if they presented with signs and symptoms of heart disease.

The analysis included a total of $28(10 \%)$ patients with confirmed SI-NENs and diagnosed CHD based on signs and symptoms, typically CHD-related cardiac involvement, 
detected using TTE and interpreted by a physician familiar with cardiac abnormalities caused by CHD. All subjects with thickened and retracted tricuspid valve leaflets failing to coapt and moderate or severe regurgitation confirmed by doppler echocardiography were included.

Of these 28 patients during the follow-up, 6 were referred for cardiac valve procedures and were further evaluated. The decision of whether to replace a valve was based on a multidisciplinary assessment of overall operability in relation to the oncological status and cardiac function. Patients with symptomatic right heart failure or ventricular dysfunction and with at least a 12-month survival prediction due to their oncologic status were operated on.

Early mortality was defined as mortality (of any cause) during hospitalization for valve surgery, or within 30 days of admission. Complications were identified through the application of institutional protocols and definitions.

Half of the study group comprised patients with well-differentiated (G1) SI-NEN and half with moderately differentiated (G2) SI-NEN. Clinical and pathological data were analyzed and summarized in Table 1.

\section{Statistical analysis}

Categorical variables were summarized using percentages and counts. Mean and standard deviations (SD) were used to report results. Median overall survival (OS) and the interquartile range (IQR) were determined using the Kaplan-Meier method in all patients and calculated from the time of the initial diagnosis of SI-NEN to either the date of death or the last follow-up visit. All statistical calculations were carried out using the Dell Inc. (2016), Dell Statistica (data analysis software system), version 13 (StatSoft Inc., Tulsa, OK, US)

\section{RESULTS AND DISCUSSION}

This study represents one of the largest series of patients with SI-NEN-related CHD in Poland as they were diagnosed and treated, with a long-term clinical follow-up.

Six patients at a mean (SD) age of 52 (11) years were included. The median overall survival (IQR) for all patients having undergone valve surgery $(n=6)$ was 40.22 (29.77-53.11) months. All patients had severe tricuspid valve regurgitation (TR) and typical CHD valve leaflet abnormalities seen in TTE (Table 1). Pulmonary valve regurgitation, either mild $(50 \%)$ or severe $(17 \%)$, was found in $67 \%$ of patients.

All patients were coordinated by an experienced multidisciplinary team during the peri-operative period, and to reduce the likelihood of a carcinoid crisis, were given a somatostatin analog infusion before and throughout the cardiac procedure until they were hemodynamically stable and off inotropes. Tricuspid valve replacements (TVR) were performed in all patients. A concomitant pulmonary valve replacement (PVR) was performed in one patient, and a mitral valve replacement (MVR) in one patient. There were no aortic valve replacements. Bioprosthetic valves were used in 5 (83\%) patients. In one patient with metastasis to the right ovary, tricuspid valve repair with placement of an annular ring CE $28 \mathrm{~mm}$ and concomitant MVR with a mechanical prosthesis was used. A bioprosthetic valve was also used in one PVR. During the postoperative period, one patient suffered from cardiac tamponade treated with pericardiocentesis and needed implantation of a pacemaker due to a third-degree atrioventricular block. One patient suffered from a stroke with temporary right-sided hemiparesis. One patient died during open-heart surgery due to cardiac failure, and another died of progressive HF in the perioperative period. As a result, early mortality following surgery, which was observed in two patients, was estimated to be $33 \%$ in our study. This is consistent with Mayo Clinic findings ranging from 9 to $29 \%$ over the years [3].

In all remaining patients, we observed improvement in symptoms such as dyspnea and peripheral edema during the early follow-up, which supported previous findings that valve replacement surgery alleviates CHD symptoms [5]. These findings indicate that valve surgery may be considered in patients with symptomatic severe right heart valve disease to relieve their symptoms.

In our analysis, in which there was no loss of follow-up, 1-year survival was noted in 4 patients (67\%), and 3-year survival in 2 subjects (33\%). The cause of death in the follow-up period was commonly associated with the progressive tumor burden and recurrent pleural effusion found in one patient. An analysis by Bhattacharyya et al. reported one- and 2-year survival rates of $56 \%$ and $44 \%$, respectively. In other short case series, survival rates closely matched our findings [6, 7].

The selection of the type of valve (biological or mechanical valve prosthesis) is a complex decision that should be made based on the patient's specific risk of bleeding, the specific tumor-related life expectancy, and potential future therapeutic interventions [8]. According to a prior study, surgery of the left-sided valves is not associated with poorer outcomes and should be done simultaneously with right-sided valve surgery, if necessary, as in our analyzed patient [4]. As reported in studies, earlier intervention enhances outcomes [3]. Currently, valve replacement surgery in CHD patients is indicated for symptomatic individuals. However, in the case of uncontrolled CS or a progressive carcinoid tumor, a significant number of symptomatic patients are not referred for valve surgery [5]. These findings suggest that all patients with SI-NENs require frequent cyclic analysis of their clinical status and TTE performance (every 3-6 months) to identify the initial development of CHD.

There is a continued development of surgical techniques for patients with TR. The use of a first-generation transcatheter tricuspid valve implantation device to treat severe symptomatic functional TR is linked to an improvement in the functional status with tolerable in-hospital mortality [9]. The transcatheter tricuspid edge-to-edge 
Table 1. Patients undergoing valve surgery for carcinoid heart disease

\begin{tabular}{|c|c|c|c|c|c|c|}
\hline & Patient 1 & Patient 2 & Patient 3 & Patient 4 & Patient 5 & Patient 6 \\
\hline Sex & Male & Female & Female & Male & Female & Male \\
\hline $\begin{array}{l}\text { Age of initial diagnosis of SI-NEN, } \\
\text { years }\end{array}$ & 36 & 45 & 50 & 69 & 50 & 63 \\
\hline Histopathological grade & NET G2 & NET G1 & NET G1 & NET G2 & NET G2 & NET G1 \\
\hline $\begin{array}{l}\text { Size of the primary tumor (patho- } \\
\text { logy), } \mathrm{mm}\end{array}$ & 20 & 69 & 40 & 10 & 45 & 20 \\
\hline $\mathrm{Ki}-67, \%$ & 10 & 1 & 2 & 5 & 3 & 2 \\
\hline pT (initial) & 3 & $x$ & 3 & 2 & No data & $x$ \\
\hline $\begin{array}{l}\mathrm{N} \text { base on surgery/ follow-up/ } \\
\text { /imaging }\end{array}$ & 1 & 1 & 1 & 1 & 1 & 1 \\
\hline $\begin{array}{l}\mathrm{M} \text { base on surgery/follow-up/ } \\
\text { /imaging }\end{array}$ & 1 & 1 & 1 & 1 & 1 & 1 \\
\hline Primary tumor resection & No & No & Yes & Yes & Yes & No \\
\hline Comorbidities & None & $\begin{array}{l}\text { Atrial hyperten- } \\
\text { sion, chronic } \\
\text { kidney disease } \\
\text { stage } 3\end{array}$ & $\begin{array}{l}\text { Multiple sclerosis, } \\
\text { after uterine } \\
\text { appendages } \\
\text { resection }\end{array}$ & $\begin{array}{l}\text { Atrial hyperten- } \\
\text { sion, thrombo- } \\
\text { cytopenia, mild } \\
\text { anemia }\end{array}$ & $\begin{array}{l}\text { Atrial hyperten- } \\
\text { sion }\end{array}$ & $\begin{array}{l}\text { Atrial hyperten- } \\
\text { sion }\end{array}$ \\
\hline Carcinoid syndrome symptoms & Yes & Yes & No & Yes & Yes & Yes \\
\hline LVEF, \% & 65 & 62 & 55 & 62 & 60 & 60 \\
\hline Mitral valve regurgitation & Mild & Mild & Severe & Mild & None & None \\
\hline Tricuspid valve regurgitation & Severe & Severe & Severe & Severe & Severe & Severe \\
\hline Aortic valve regurgitation & Mild & None & None & Mild & Mild & None \\
\hline Pulmonary valve regurgitation & None & Mild & Mild & Mild & Severe & None \\
\hline Preoperative NYHA class & ॥ & III & III & $\|$ & III & IV \\
\hline Type of valve surgery & TVR & TVR + PVR & $T V R+M V R$ & TVR & TVR & TVR \\
\hline Percutaneous/open heart surgery & $\begin{array}{l}\text { Open heart sur- } \\
\text { gery after failed } \\
\text { percutaneous } \\
\text { procedure }\end{array}$ & $\begin{array}{l}\text { Open heart } \\
\text { surgery }\end{array}$ & $\begin{array}{l}\text { Open heart } \\
\text { surgery }\end{array}$ & $\begin{array}{l}\text { Open heart sur- } \\
\text { gery after failed } \\
\text { percutaneous } \\
\text { procedure }\end{array}$ & $\begin{array}{l}\text { Open heart } \\
\text { surgery }\end{array}$ & $\begin{array}{l}\text { Open heart } \\
\text { surgery }\end{array}$ \\
\hline $\begin{array}{l}\text { Concomitant procedures: } C A B G \text { or } \\
\text { ASD/PFO repair }\end{array}$ & None & None & None & None & None & None \\
\hline Early complications & $\begin{array}{l}\text { Tamponade in } \\
\text { perioperative pe- } \\
\text { riod, pacemaker } \\
\text { implantation due } \\
\text { to third-de- } \\
\text { gree atrio-ventri- } \\
\text { cular block }\end{array}$ & No & No & $\begin{array}{l}\text { Died due to } \\
\text { progression of } \\
\text { cardiac failure }\end{array}$ & $\begin{array}{l}\text { Stroke with } \\
\text { temporary } \\
\text { right-sided } \\
\text { hemiparesis }\end{array}$ & $\begin{array}{c}\text { Died during } \\
\text { cardiac surgery } \\
\text { due to cardiac } \\
\text { failure }\end{array}$ \\
\hline Overall survival, months & 30 & 70 & 43 & 49 & 27 & 34 \\
\hline Survival after valve surgery & $\sim 3$ years & $\sim 1$ year & $\sim 3$ years & $<1$ month & 1 year & $<1$ month \\
\hline Cause of death & - & $\begin{array}{l}\text { Died due to recu- } \\
\text { rrent pleural ef- } \\
\text { fusion and tumor } \\
\text { progression }\end{array}$ & - & $\begin{array}{l}\text { Died due to } \\
\text { progression of } \\
\text { heart failure }\end{array}$ & $\begin{array}{l}\text { Progressive } \\
\text { cachexia. Died } \\
\text { due to tumor } \\
\text { progression }\end{array}$ & $\begin{array}{c}\text { Died during } \\
\text { cardiac surgery } \\
\text { due to cardiac } \\
\text { failure }\end{array}$ \\
\hline
\end{tabular}

Abbreviations: ASD, atrial septal defect; CABG, coronary artery bypass grafting; LVEF, left ventricular ejection fraction; MVR, mitral valve replacement; NET, neuroendocrine tumours; NYHA, New York Heart Association; PVR, pulmonary valve replacement; SI-NEN, neuroendocrine neoplasms of the small intestine; TVR, tricuspid valve replacement

repair may be a safe and possibly effective treatment for patients with HF and significant TR, leading to the reduction of TR's severity severity and clinical improvement [10].

In conclusion, carcinoid heart disease remains a tremendous challenge despite medical and surgical advances in this field. The mortality rates suggest that valve surgery for CHD is a high-risk procedure, but it might be valuable to patients with symptomatic severe right heart valve disease with at least a 12-month survival prediction due to symptomatic improvement. However, short-term mortality after valve replacement for $\mathrm{CHD}$ decreased in the present era, and overall survival is mostly limited by tumor progression. Patient selection, thorough preoperative planning, and perioperative management protocols, all under the supervision of a multidisciplinary team, are essential to succeed.

\section{Article information}

Conflict of interest: None declared.

Open access: This article is available in open access under Creative Common Attribution-Non-Commercial-No Derivatives 4.0 International (CC BY-NC-ND 4.0) license, allowing to download articles and share them with others as long as they credit the authors and the publisher, but without permission to change them in any way or use them commercially. For commercial use, please contact the journal office at kardiologiapolska@ptkardio.pl.

\section{REFERENCES}

1. Niederle B, Pape UF, Costa F, et al. ENETS Consensus Guidelines Update for Neuroendocrine Neoplasms of the Jejunum and Ileum. Neuroendocrinology. 2016; 103(2): 125-138, doi: 10.1159/000443170, indexed in Pubmed: 26758972.

2. Gut P, Czarnywojtek A, Sawicka-Gutaj N, et al. Assessment of serotonin concentration in patients with a small-intestine neuroendocrine neoplasm and carcinoid syndrome treated with somatostatin analogues. Pol Arch 
Intern Med. 2020; 130(10): 903-905, doi: 10.20452/pamw.15504, indexed in Pubmed: 32643913.

3. Nguyen A, Schaff HV, Abel MD, et al. Improving outcome of valve replacement for carcinoid heart disease. J Thorac Cardiovasc Surg. 2019; 158(1): 99-107.e2, doi: 10.1016/j.jtcvs.2018.09.025, indexed in Pubmed: 30527716.

4. Albåge $A$, Montibello M. Surgical aspects of valve replacement in carcinoid heart disease. J Card Surg. 2021; 36(1): 290-294, doi: 10.1111/jocs.15169, indexed in Pubmed: 33124055.

5. Bhattacharyya S, Raja SG, Toumpanakis C, et al. Outcomes, risks and complications of cardiac surgery for carcinoid heart disease. Eur J Cardiothorac Surg. 2011; 40(1): 168-172, doi: 10.1016/j.ejcts.2010.10.035, indexed in Pubmed: 21156347.

6. Mokhles $\mathrm{P}$, van Herwerden $\mathrm{LA}$, de Jong $\mathrm{PL}$, et al. Carcinoid heart disease: outcomes after surgical valve replacement. Eur J Cardiothorac Surg. 2012; 41(6): 1278-1283, doi: 10.1093/ejcts/ezr227, indexed in Pubmed: 22219480.
7. Edwards NC, Yuan M, Nolan O, et al. Effect of valvular surgery in carcinoid heart disease: an observational cohort study. J Clin Endocrinol Metab. 2016; 101(1): 183-190, doi: 10.1210/jc.2015-3295, indexed in Pubmed: 26580239.

8. Florczak E, Pęczkowska M, Konka M, et al. A 51-year-old patient with carcinoid heart disease and severe tricuspid regurgitation. Kardiol Pol.2017; 75(2): 183, doi: 10.5603/KP.2017.0027, indexed in Pubmed: 28205198.

9. Hahn RT, Kodali S, Fam N, et al. Early multinational experience of transcatheter tricuspid valve replacement for treating severe tricuspid regurgitation. JACC Cardiovasc Interv. 2020; 13(21): 2482-2493, doi: 10.1016/j. jcin.2020.07.008, indexed in Pubmed: 33153565.

10. Rdzanek A, Szymański P, Gackowski A, et al. Percutaneous tricuspid edge-to-edge repair - patient selection, imaging considerations, and the procedural technique. Expert opinion of the Working Group on Echocardiography and Association of CardioVascular Interventions of the Polish Cardiac Society. Kardiol Pol. 2021; 79(10): 1178-1191, doi: 10.33963/KP.a2021.0125, indexed in Pubmed: 34611879. 